\title{
The human vaccinia-related kinase 1 (VRK1) phosphorylates threonine-18 within the mdm-2 binding site of the p53 tumour suppressor protein
}

\author{
Susana Lopez-Borges ${ }^{1,2}$ and Pedro A Lazo*,1,2 \\ ${ }^{1}$ Centro de Investigación del Cáncer, Instituto de Biología Molecular y Celular del Cáncer, Consejo Superior de Investigaciones \\ Cientificas, Universidad de Salamanca, Campus Miguel de Unamuno, 37007 Salamanca, Spain; ${ }^{2}$ Unidad de Genética y Medicina \\ Molecular, CSIC-Centro Nacional de Biologia Fundamental, Instituto de Salud Carlos III, 28220 Majadahonda, Spain
}

The tumour suppressor p53 protein integrates multiple signals regulating cell cycle progression and apoptosis. This regulation is mediated by several kinases that phosphorylate specific residues in the different functional domains of the $\mathbf{5 3}$ molecule. The human VRK1 protein is a new kinase related to a poxvirus kinase, and more distantly to the casein kinase 1 family. We have characterized the biochemical properties of human VRK1 from HeLa cells. VRK1 has a strong autophosphorylating activity in several Ser and Thr residues. VRK-1 phosphorylates acidic proteins, such as phosvitin and casein, and basic proteins such as histone $2 \mathrm{~b}$ and myelin basic protein. Because some transcription factors are regulated by phosphorylation, we tested as substrates the N-transactivation domains of p53 and c-Jun fused to GST. Human c-Jun is not phosphorylated by VRK1. VRK1 phosphorylates murine p53 in threonine 18. This threonine is within the p53 hydrophobic loop (residues $13-23)$ required for the interaction of $p 53$ with the cleft of its inhibitor mdm-2. The VRK1 C-terminus domain (residues 268-396) that contains a nuclear localization signal targets the protein to the nucleus, as determined by using fusion proteins with the green fluorescent protein. We conclude that VRK1 is an upstream regulator of p53 that belongs to a new signalling pathway. Oncogene (2000) 19, 3656-3664.

Keywords: VRK1; p53; mdm-2; kinase; autophosphorylation, nuclear localization signal

\section{Introduction}

Reversible protein phosphorylation on serine, threonine or tyrosine residues is an essential mechanism for the regulation of multiple cellular functions including cell cycle and apoptosis (Hunter, 1995; Karin and Hunter, 1995). Kinases and phosphatases mediate this control. Protein kinases, which transfer a phosphate group to a hydroxyl acceptor, form a very large gene family and can be divided in two major groups depending on whether they phosphorylate serine/ threonine or tyrosine residues, with their structural conservation mainly localized in their catalytic domain (Hunter, 1995). Some human poxviruses, such as vaccinia and variola, contain a gene coding for a

*Correspondence: PA Lazo, Centro de Investigación del Cáncer, CSIC-Universidad de Salamanca, Campus Miguel de Unamuno, 37007 Salamanca, Spain

Received 28 February 2000; revised 23 May 2000; accepted 25 May 2000 serine-threonine kinase, B1Rin vaccinia, that is expressed early during viral infection (Banham and Smith, 1992; Beaud et al., 1995; Lin et al., 1992). $\mathrm{B} 1 \mathrm{R}$ is implicated in the control of viral DNA replication (Rempel et al., 1990; Rempel and Traktman, 1992; Traktman et al., 1989). Recently in a search for novel human genes, two EST sequences were identified that have homology to this $\mathrm{B} 1 \mathrm{R}$ vaccinia virus kinase, named human VRK1 and 2 for vaccinia related kinases 1 and 2 (Nezu et al., 1997). Based on this DNA homology, they were postulated to be two novel serine-threonine kinases (Nezu et al., 1997). VRK1 and VRK2 cDNA code for proteins of 396 and 508 amino acids respectively. The VRK1 gene maps to human $14 q 23$ region and VRK2 gene maps to 2p15-16 chromosome region (Nezu et al., 1997), and both are expressed in different cell types suggesting that their expression is tissue specific and developmentally regulated (Nezu et al., 1997). However nothing is known about the biochemical properties of these two new human protein kinases or their biological roles.

Among the proteins known to be regulated by reversible phosphorylation are many transcription factors, among which p53 is included. The tumour suppressor p53 protein plays a central role in several aspects of cellular regulation, which includes modulation of cell cycle progression and apoptosis (Brown and Wouters, 1999; Giaccia and Kastan, 1998; Levine, 1997; Prives and Hall, 1999). The p53 protein can be modulated by reversible phosphorylation that occurs in at least 11 different Ser or Thr residues, located in different functional domains of the murine p53 molecule (Meek, 1998a,b; 1999). These phosphorylations occur in response to specific types of stimulation (Meek, 1999), such as DNA damage (Lakin et al., 1999; Lakin and Jackson, 1999; Shieh et al., 1997; Siliciano et al., 1997). In the murine p53 N-terminus transactivation domain, casein kinase $1 \mathrm{D}(\delta)$ and $\mathrm{E}(\varepsilon)$ phosphorylate Ser-4, Ser-6 and Ser-9 (Knippschild et al., 1996; 1997; Milne et al., 1992). Ser-15 is phosphorylated by at least three kinases in response to DNA damage, such as DNA-dependent protein kinase (Shieh et al., 1997; Siliciano et al., 1997; Dumaz and Meek, 1999), the ATM protein (Banin et al., 1998; Canman et al., 1998; Siliciano et al., 1997), the ataxiatelangiectasia related (ATR) protein (Banin et al., 1998; Hall-Jackson et al., 1999; Lakin et al., 1999). Ser-15 phosphorylation alters the strength of p53 as a transcription factor (Dumaz and Meek, 1999), and also impairs p53 apoptotic activity (Unger et al., 1999). Ser-34 is phosphorylated by a Jun kinase (Milne et al., 1995). Ser37 is also phosphorylated by ATR protein (Tibbetts et al., 1999), and DNA-PK (Shieh et al., 
1997). Thr-73 and -83 are phosphorylated by MAPK (Milne et al., 1994). In human p53, Ser-33 is phosphorylated by the complex CDK7-cyclin $\mathrm{H}$ (Ko et al., 1997). More recently it has been reported the phosphorylation of Ser-20 by the human homologues of yeast checkpoint kinases Chk1 and Cds1 (Chehab et al., 1999; Hirao et al., 2000; Shieh et al., 2000a,b). Also phosphorylation of Thr-18 has been reported as mediated by casein kinases (Dumaz et al., 1999; Sakaguchi et al., 2000), requiring the previous phosphorylation of Ser-15, and this phosphorylation interferes with the p53 binding to mdm-2 (Bottger et al., 1999; Craig et al., 1999), and have some effect on p53-dependent transcription (Dumaz and Meek, 1999). In the p53 C-terminus, Ser-309 is phosphorylated by cyclin dependent kinases, Ser-370 and Thr-372 by protein kinase $\mathrm{C}$, and $\mathrm{Ser}-386$ by casein kinase 2 (reviewed in Meek (1998a,b)). The biological effects of these phosphorylations can be a consequence of the alteration of the p53 role as a transcription factor (Levine, 1997; Meek, 1999), depending on the residue phosphorylated as determined in assays with reporter gene constructs (Dumaz and Meek, 1999). Within the $\mathrm{N}$-terminus p53 transactivation domain is located the highly conserved hydrophobic loop that mediates p53 binding to the inhibitory $\mathrm{mdm}-2$ protein. Mdm-2 binding promotes shuttling of p53 from the nuclei to the cytoplasm and targets p53 for ubiquitin mediated degradation (Levine, 1997). The p53 binding site to mdm-2 is highly conserved among different species, from trout to humans (Levine, 1997). Phosphorylation of Thr-18 interferes with p53 binding to mdm-2 (Craig et al., 1999). However, depending on the species, there are some differences in the biological responses, which are likely to be the result of the sequence variation in other less well conserved domains of the p53 molecule. Therefore, p53 phosphorylation might have different biological results depending on the species. Considering the major role that phosphorylation plays in p53 biology, we studied if VRK1 could be a new protein kinase implicated in its regulation.

In this study we have characterized and shown that human VRK1 is a novel serine-threonine kinase related to the vaccinia $\mathrm{B} 1 \mathrm{R}$ kinase. These kinases are related to the large group of casein kinases type 1, and to other Ser-Thr kinases in their catalytic domain. However, VRK1 has some distinct biochemical properties, which make it indeed a new type of Ser-Thr kinase. This kinase has a very active autophosphorylation potential, and is present in the nucleus. Among its substrates, VRK1 is able to phosphorylate Thr-18 in the N-terminus transactivation domain of murine p53, within the mdm-2 binding region. The VRK1 protein might be a novel upstream regulator of $\mathrm{p} 53$, and the beginning of the characterization of a new and not yet identified signalling pathway.

\section{Results}

The $N$-terminus of VRK1 protein is related to the catalytic domain of casein kinase 1

To try to understand the VRK1 protein role, we first determined how it related to other protein kinases. For this aim we performed a BLAST search of the
GenBank and Swiss-Prot databases with the human VRK1 amino acid sequence to identify the most closely VRK1 related, viral and non-viral, proteins. These protein sequences were reanalysed using the Kimura algorithm for protein similarity in order to identify related groups. Similar results were obtained using the CLUSTAL W program for multiple protein alignment. For these second homology analysis only the region comprising their catalytic domain were used because in this region was concentrated the significant homologies. In that way the distortion introduced by their very different, and non-related, carboxy terminal or regulatory domains could be avoided. The result of this analysis is shown in Figure 1a. The VRK1 group of protein kinases, composed by VRK1, VRK2 and the
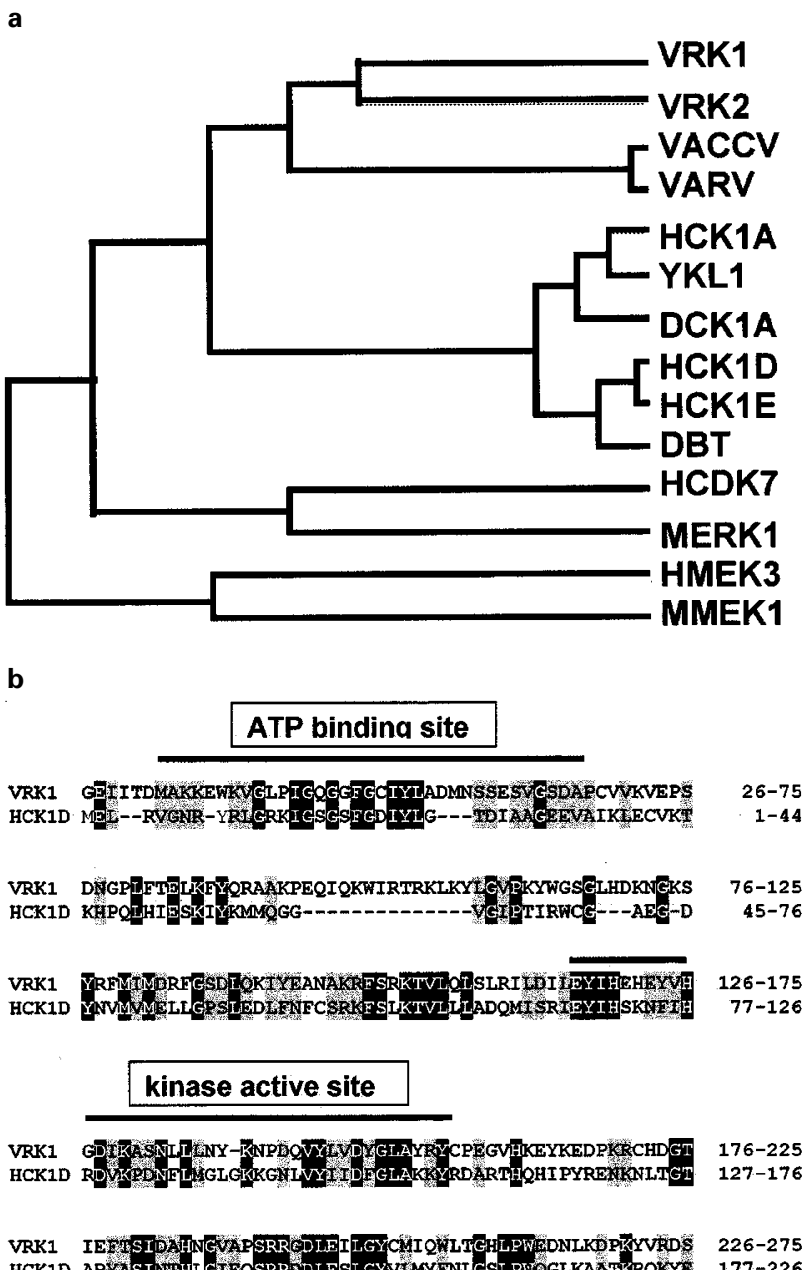

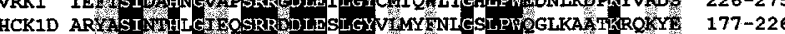

VRK1 KTRYRENIASLMDKCFPEKNKPGEIAKYMETMKLIDYTEKPLYENIRDII 276-325 HCKID FI SEKKMSTP IEVLCKGYPSEFATYLAFCRSGRFDDKPDYSYLRELFRNL 227-276

Figure 1 (a) Similarity of VRK1 to other protein kinases. The analysis was performed using the Kimura protein distance algorithm and the UPGMA program and CLUSTAL $\mathrm{W}$ as implemented in the Oxford Molecular software. Human CK1A (P48729), 1D (P48730) and 1E (P49674): human casein kinase 1 A, D and E; YKL1: Caenorhabditis elegans casein kinase 1 (P42168); DCK1A: Drosophila melanogaster casein kinase 1 A (P54367). VARVV (P33800) and VACCV (P16913): variola and vaccinia kinase. MERK1 (PQ63844), hMEK3 (Q99759), mMEK1 (P53349). The Swiss-Prot database entry number is in parenthesis. (b) Homology between the VRK 1 and casein kinase $1 \delta$ catalytic domains. Identical residues are boxed, and similar residues are within shaded area. The location of the ATP binding site and the catalytic site are indicated 
vaccinia and smallpox virus kinases, forms a clearly independent evolutionary branch. This kinase group is close to the casein kinase type 1 family (Gross and Anderson, 1998), and is far more distantly related to the next group of Ser-Thr kinases, which include several kinases implicated in signal transduction processes, such as CDK7, ERK1, MEK1 or MEK3 (Figure 1a). Within the CK1 group, VRK1 is more proximal to CK1D $(\delta)$ and E $(\varepsilon)$, and their Drosophila homologue, $d b t$ that appears to modulate circadian rhythms (Kloss et al., 1998; Price et al., 1998). This homology is mainly restricted to the VRK1 N-terminal 300 amino acids. The alignment of human VRK1 and casein kinase $1 \delta$ (CK1D) amino termini is shown in Figure $1 \mathrm{~b}$. VRK-1 has a unique C-terminus (residues $300-396$ ) with no homology to any other known protein in public databases (not shown). This Cterminus might mediate specific interactions with other proteins, or play a regulatory role not yet identified.

\section{VRK1 has an autophosphorylating activity}

To characterize the biochemical properties of the VRK1 protein we made a fusion protein with the
VRK1 coding region and the glutathione-S-transferase (GST-VRK1). This fusion protein has a size of approximately $70 \mathrm{kDa}$, corresponding to the 45 and $27 \mathrm{kDa}$ of VRK1 and GST moieties respectively. To demonstrate if this fusion protein has autophosphorylation activity, we performed a standard in vitro kinase assay in the absence of any other protein as substrate. After carrying out a kinase assay, a $70 \mathrm{kDa}$ protein was detected (lane 1, Figure 2a), and following its digestion with thrombin, only the $45 \mathrm{kDa}$ band is detected as phosphorylated (lane 3, Figure 2a). This band corresponds to the VRK1 moiety of the fusion protein. To determine if VRK1 protein is active by itself, the GST-VRK1 fusion protein was first digested with thrombin, to separate in the VRK1 and GST moieties, followed by a kinase assay. In that case only a band of $45 \mathrm{kDa}$ was detected (lane 2, Figure 2a). The reduced activity of the free VRK1 protein, first digested with thrombin, is a likely consequence of the protease treatment, because the VRK1 moiety of the fusion protein has thrombin target sequences. We conclude from this experiment that the kinase activity is an intrinsic property of VRK1, which does not appear to be affected by its fusion to GST.
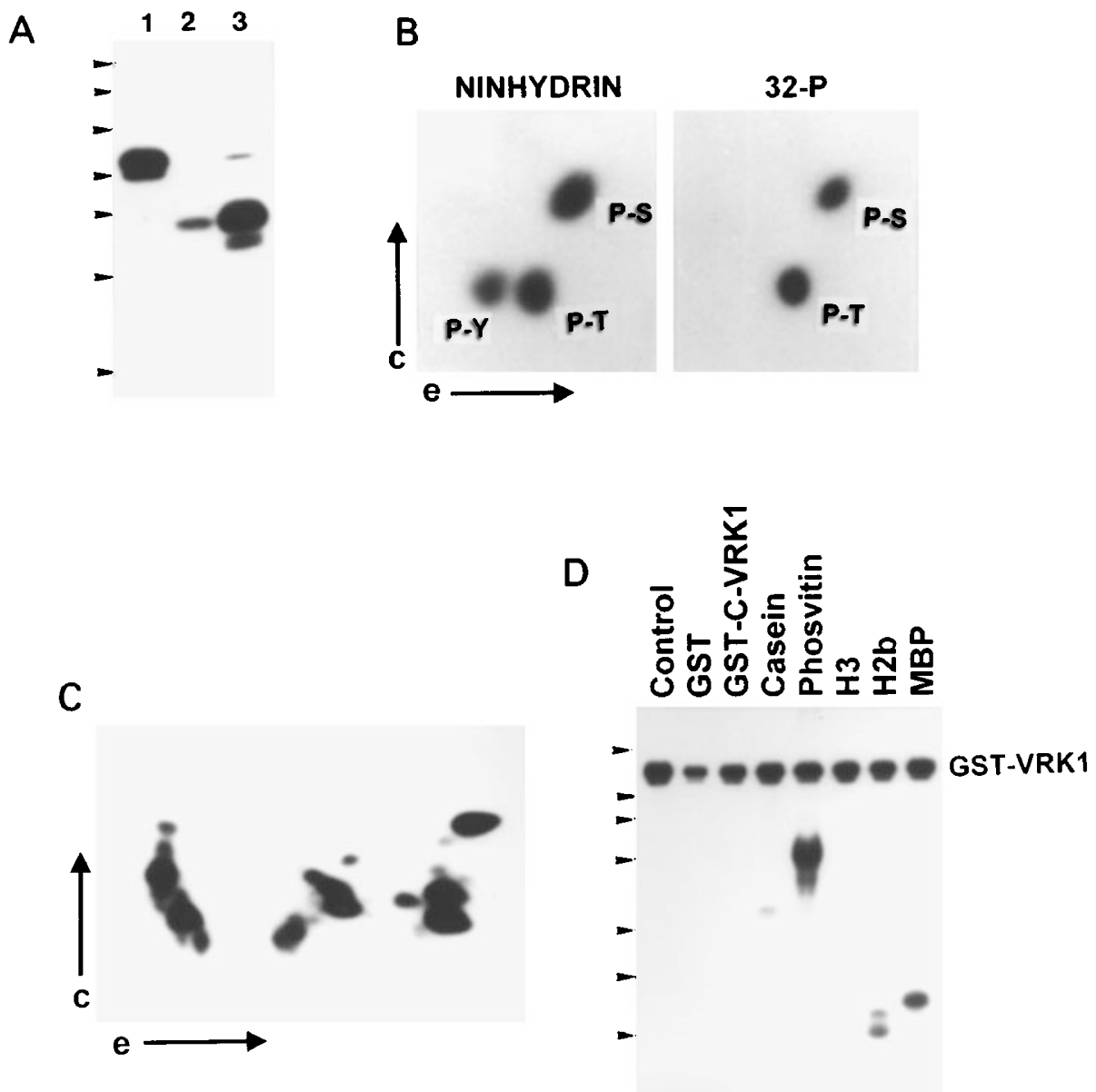

Figure 2 Biochemical properties of VRK1 protein. (a) Autophosphorylation reactions of GST-VRK1 fusion protein and free VRK1. Free VRK1 was prepared by digestion of the fusion protein with thrombin. In lane 1 is shown the autophosphorylated GST-VRK1 fusion protein. In lane 2, the GST-VRK1 protein was first digested with thrombin, to release the VRK1 moiety, followed by an autophosphorylation reaction. In lane 3, the GST-VRK1 protein was first autophosphorylated, followed by thrombin digestion to identify the phosphorylated moiety. (b) Identification of phosphorylated residues in two dimension high voltage flat bed electrophoresis which were developed with ninhydrin (left) or by autoradiography (right). (c) Trypsin phosphopeptide map of autophosphorylated wild-type GST-VRK-1 protein analysed in two dimensions by electrophoresis and chromatography. (d) Protein substrates used by kinase activity of GST-VRK-1. GST-C-VRK1 is a fusion protein with the carboxy terminus of VRK1 (residues 268-396) 
VRK1 is autophosphorylated in several Ser and Thr residues

To identify the type of amino acid residue phosphorylated by the VRK1 activity we performed an autophosphorylation reaction with the GST-VRK1 fusion protein. The phosphorylated protein was isolated, hydrolyzed with acid treatment, and analysed in two dimensions by electrophoresis. Incorporation of radioactive phosphate was only detected in Ser and Thr, but not in Tyr residues (Figure 2b). These results demonstrate that the VRK1 kinase activity is indeed a serine-threonine kinase, and that at least two residues, one of each type, are phosphorylated in the VRK1 protein. Next we attempted to identify the individual amino acids residues modified by phosphorylation. For this purpose we introduced in the GSTVRK1 fusion protein several amino acid substitutions in positions which might be likely targets for phosphorylation. To select the residues to be changed, the VRK1 protein sequence was analysed by a program in the Omiga software (Oxford Molecular) designed to detect putative target sequences for several known kinase activities. Residues located outside the ATP binding site and the catalytic domain of VRK1 were selected for amino acid substitutions by in vitro site-directed mutagenesis. The substitutions introduced to attempt to detect if any of them was phosphorylated were Ser-14-Ala, Thr-102-Ala, Ser-125-Gly, Ser-150Ala, Ser-158-Gly, Ser-239-Ala, Thr-305-Ala, Thr-312Ala, Thr-355-Ala and Thr-390-Ala. All the mutant GST-VRK1 proteins contained an individual aminoacid substitution. These experiments were performed using GST-VRK-1 normal or the corresponding mutant proteins in an autophosphorylation reaction. All mutant proteins retained their autophosphorylating activity in both Ser and Thr residues (not shown). Because two residues can be modified, the phosphorylated proteins were digested to completion with trypsin and their phosphopeptide map was determined in a two-dimensional analysis, consisting of high voltage electrophoresis and thin layer chromatography. The result obtained with the wild type GST-VRK1 fusion protein shows a very complex pattern of phosphorylation with multiple radioactive phosphopeptides (Figure 2c). Two types of intensities could be detected in the phosphopeptides, seven have a strong intensity and several othersa much weaker intensity. These data indicated that several residues are phosphorylated in this protein. In all the mutants with a single amino acid substitution, the same phosphopeptide map was obtained without any apparent quantitative or qualitative difference (not shown). To try to determine if there was an order in the phosphorylation of different peptides, a time course of the GST-VRK1 autophosphorylation reaction was carried out. The same pattern, both in number of phosphopeptides and their relative intensity, was observed at both short (30 min) or long kinase reaction times (24 h) (not shown). These data suggested that the difference in relative intensities of the peptides is a consequence of the relative preference for the target residue, and does not suggest an order in which a group of residues are more rapidly phosphorylated than others. The detection of a large number of phosphorylated peptides indicates that in the VRK1 protein there are many amino acid residues that are potential kinase targets for autophosphorylation in trans.

\section{$V R K 1$ protein substrates in relation to other casein kinases}

We next determined the biochemical properties of the VRK1 activity with regard to established kinase substrates. The proteins used as substrates were selected based on their previous use either as substrates of the casein kinase protein family, or as substrates of the vaccinia $\mathrm{B} 1 \mathrm{R}$ kinase. In that way we can relate the pattern of substrate phosphorylation by VRK1 to what is known from the more closely related kinases. For this aim an assay was performed with the full length GST-VRK1 protein using as substrates, casein, phosvitin, histone $2 \mathrm{~b}$, histone 3 , and myelin basic protein (MBP). The results are shown in Figure $2 \mathrm{~d}$. The GST-VRK1 protein phosphorylates the acidic proteins, phosvitin more strongly than casein. VRK also phosphorylates basic proteins, such as MBP, a substrate of MAPK (Ceci et al., 1997), and histone 2b, a substrate of the PKB/Akt kinase (Bellacosa et al., 1998). VRK1 does not phosphorylate histone 3. The VRK1 kinase activity does not phosphorylate GST or GST-C-VRK1, containing the carboxy terminus, residues 268-396, of VRK1 (Figure 2d). However, probably because of its many target residues, the GSTVRK1 protein incorporates many more phosphoryl groups than other target protein substrates, as evidenced by their relative band intensity in the gels.

\section{Phosphorylation of transcription factors by VRK1}

Many proteins implicated in transcriptional control are regulated by reversible phosphorylation (Karin and Hunter, 1995; Weigel, 1996). We decided to test if the kinase activity of the human VRK1 protein was able to phosphorylate transcription factors that are known to be regulated by phosphorylation, such as c-Jun and the tumour-suppressor p53 protein, given their central role in cellular responses to stress signals. As substrates for phosphorylation we used several GST-fusion proteins with the N-terminus (transactivation domains) of both human c-jun and murine p53. For c-jun the GST-jun protein has residues $1-79$. For p53 the several GSTp53 fusion proteins used were derived from the 1-85 region. GST-p53 is strongly phosphorylated as shown with GST-p53 fusion proteins, FP221 (amino acids 185), FP267 (amino acids 1-64), FP 279 (11-65), and mutant FP380 (1-85 with three Ser to Ala substitutions in positions 4, 6 and 9) (Figure 3a). The phosphorylation of these GST-p53 fusion proteins suggested there is at least one phosphorylated amino acid within residues 11-65 (FP279) (Figure 3a). However, there might be an additional phosphorylated amino acid within residues $1-10$ or $66-85$.

\section{VRK1 phosphorylates p53 in Thr-18}

In order to identify the specific residues phosphorylated by VRK1, several amino acid substitutions were made in all phosphorylatable residues within the p53 $\mathrm{N}$-terminus domain from residues $1-85$ in murine $\mathrm{p} 53$. We first studied the region comprising residues $11-65$, we introduced amino acid substitutions in all poten- 
A

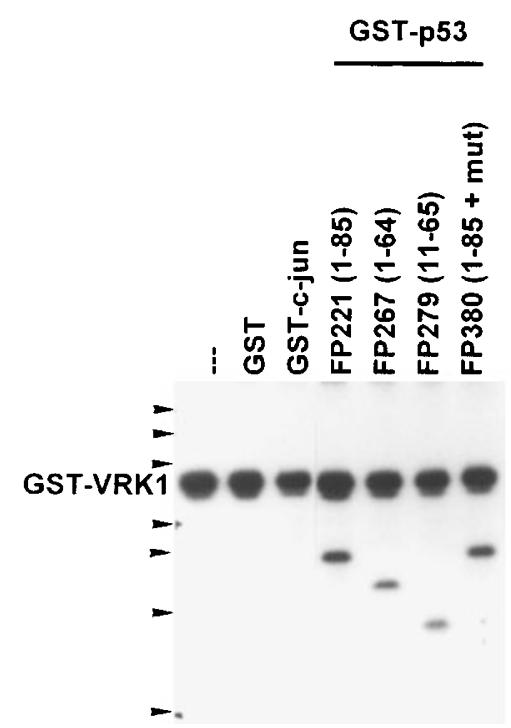

B
GST-p53

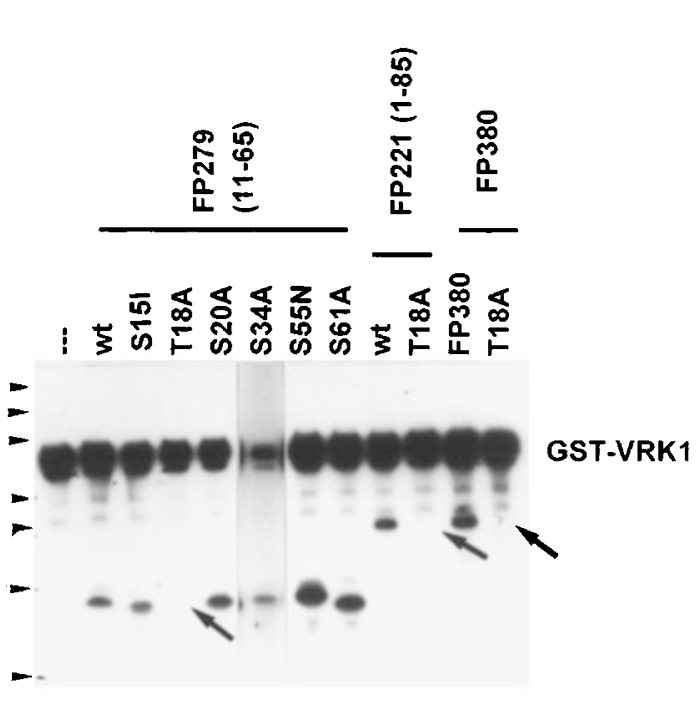

Figure 3 p53 as target of VRK1 activity. (a) Proteins phosphorylated by GST-VRK-1 activity. C: control GST-VRK-1; GST; GST-c-jun; and GST-p53 fusion proteins (FP), the p53 residues are indicated in parenthesis. (b) Phosphorylation by GST-VRK1 of murine GST-p53 fusion proteins containing different amino acid substitutions. Substitutions were introduced in the region from amino acids 11 - 63 of murine p53 (FP279): PF15 (Ser-15-Ile), PF18 (Thr-18-Ala), PF20 (Ser-20-Ala), PF34 (Ser-34-Ala), PF55 (Ser55-Asn), and PF61 (Ser-61-Ala). Other mutations were introduced in region 1-85. PF221/18 has only the T18A substitution, and PF380/18, has in addition to the Thr-18-Ala, substituted to Ala the three Ser 4, 6 and 9 phosphorylated by casein kinase 1

tially phosphorylated residues using as substrates the normal GST-p53 fusion protein FP279 (Figure 3b). The aminoacid substitutions introduced in the murine p53 moiety were Ser-15-Ile (PF15), Thr-18-Ala (PF18), Ser-20-Ala (PF20), Se-34-Ala (PF34), Ser-55-Asn (PF55) and Ser-61-Ala (PF61). There was a loss of phosphorylation by VRK1 only in the p53 mutant fusion protein containing the Thr-18-Ala substitution (Figure 3b). All the other substitutions in this 11-65 region did not result in loss of p53 phosphorylation by VRK1. The Ser-15-Ile substitution resulted in a slower rate of phosphorylation of Thr-18, detected by the slightly weaker band intensity, probably as a result of steric hindrance by the bulkier side chain of isoleucine. These results, in addition to identifying Thr-18 as a target for VRK1, rule out the phosphorylation of residues known to be phosphorylated by other kinases within this p53 region, such as Ser-15 which can be phosphorylated by a double-strand DNA-dependent protein kinase (Lakin et al., 1999), and Ser-34 which is phosphorylated by a JNK (Canman et al., 1998; Milne et al., 1995; Shieh et al., 1997). Phosphorylation of Ser55 and -61 was also ruled out. To confirm that Thr-18 is the only target for VRK1, and rule out additional phosphorylation sites within residues $1-10$ and 66-85. We also introduced the Thr-18-Ala substitution in GST-p53 fusion proteins FP221 (FP221 + 18), or in the mutant FP380 (PF 380+18), that has the three casein kinase 1 serine (4, 6 and 9) targets replaced by alanine. In both cases the Thr 18-Ala substitution also resulted in the loss of phosphorylation (Figure 3b). These results confirm Thr-18 as the only p53 target for VRK1 phosphorylation. They also rule out additional phosphorylation within residues $66-85$. In this region are located the target for MAPK, Ser-73 and Ser-83, (Milne et al., 1994), as well as the CK1D $(\delta)$ and CK1E $(\varepsilon)$ target sites, Ser-4, Ser-6 and Ser-9 (Knippschild et al., 1997; Milne et al., 1992). The relevance of
Thr-18 phosphorylation is the result of its location within the hydrophobic region, residues $13-23$, that mediate p53 interaction with its mdm-2 inhibitor, and which are identical in human, rat and mice p53 (Levine, 1997). Specific phosphorylations within this hydrophobic pocket, such as Ser-15, Thr-18 or Ser-20, have different effects on the activity of p53 as a transcription factor. The role of $\mathrm{p} 53$ as transcription factor is more sensitive to Ser-15, than to Thr-18 phosphorylation (Dumaz and Meek, 1999).

\section{VRK1 protein is present in the nuclei}

Most protein kinases of the Ser-Thr type are located in the cytoplasm, as is the case of casein kinases, or the $\mathrm{B} 1 \mathrm{R}$ vaccinia kinase. However, changes in subcellular location might be mediated by the diverging C-terminal domain of the different kinases, and VRK1 contains a putative nuclear localization signal in this region. To determine the subcellular localization of the human VRK1 protein, several fusion proteins were made with the green fluorescent protein, EGFP, as tag. In the constructs, EGFP was placed in the amino terminus with respect to the VRK1 moiety. The fusion proteins were made either with the full-length VRK1 protein, construct pEGFP-VRK1, or the VRK1 protein Cterminus, residues $268-396$, which is likely to be responsible for the specific interaction of VRK1 with other proteins, construct pEGFP-C-VRK1. The Nterminus of VRK1 is not likely to be implicated in subcellular localization, because it has a very well conserved Ser-Thr kinase domain structure (Figure 1b). To detect the subcellular localization of these proteins, NIH3T3 fibroblasts were transiently transfected with $5 \mu \mathrm{g}$ of the appropriate plasmid, and 2 days after transfection the cells were analysed by fluorescence microscopy in order to identify the subcellular location of the different EGFP-VRK1 protein constructs 
expressed in transfected cells. Both, the EGFP-VRK1 (full length) and the EGFP-C-VRK1 (residues 268396) proteins were clearly detected in the nuclei, which were identified in the same preparations by Hoescht dye fluorescence (Figure 4). The VRK1 carboxy terminus contains at positions 356-360 a nuclear localization signal (NLS), a stretch of five consecutive positively charged amino acids (KKRKK). This NLS sequence is similar to that of SV40 (Dingwall \& Laskey, 1991; Powers and Forbes, 1994) and necessary for binding to importin $\alpha$ (Melchior and Gerace, 1998). The negative control protein, expressed by the vector pEGFP-C1, was diffusely distributed within the cell, and its fluorescence was very weak. Also as control for cytoplasmic and nuclear localization we used other GST fusion proteins containing human respiratory syncitial virus protein (data not shown). These results suggest that VRK1 kinase is a protein located in the nuclei.

\section{Discussion}

The primary structure of VRK1 protein is homologous to other kinases, particularly the vaccinia B1R kinase, and more distantly to members of the CK1 family (Gross and Anderson, 1998). This homology is restricted to the N-terminal 300 amino acids, corresponding to the catalytic domain, and suggested it is a Ser-Thr kinase as demonstrated in this report by in vitro kinase assays. However the VRK1 group of kinases represent a clearly independent group of kinases. Within the CK1 group, VRK1 is more proximal to CK1D $(\delta)$ and $\mathrm{E}(\varepsilon)$, and their Drosophila homologue, $d b t$ that appears to modulate circadian rhythms (Kloss et al., 1998; Price et al., 1998). VRK-1 has a unique C-terminus (residues $310-396)$ with no homology to any other known protein. The different C-terminus of these proteins might be involved in their respective specific functions and their regulation mediated specific interactions with other proteins, as shown for CK1D (Graves and Roach, 1995)

Although VRK1 is structurally related to vaccinia $\mathrm{B} 1 \mathrm{R}$ kinase there are also differences in their biochemical properties. VRK1 has a very strong autophosphorylating activity (this study) and, in this respect, it differs from B1R (Banham and Smith, 1992; Rempel and Traktman, 1992), and is related to some other Ser-Thr kinases, such as pim-1, Raf-1 or mos (Rempel and Traktman, 1992), as well as the CK1 protein family (Tuazon and Traugh, 1991). VRK1 differs from CK1 in the use of different proteins as substrates of the kinase activity. CK1 only phosphorylates some acidic proteins, such as casein, but not others like phosvitin, and do not phosphorylate basic proteins. However, VRK1 phosphorylates better phosvitin rather than casein, and also phosphorylates basic proteins, such as myelin basic protein (MBP), a substrate of the p38 and Tpl-2 MAP kinases (Ceci et al., 1997). These differences may be due to the long time after their evolutive divergence (Figure 1a). The detection of a large number of phosphorylated peptides suggests that in the VRK1 protein, many residues are susceptible of being phosphorylated. The extensive phosphorylation observed is likely to be the result of the high content in Ser and Thr residues. VRK1 has 38 of these residues that represent $10 \%$ of the protein. Amino acid sequences, which are targeted by CK1, have an acidic residue (Flotow and Roach, 1991), or a phosphoryl group (Flotow et al., 1990), located three or four residues amino terminal before the phosphorylated residue. Thus a phosphorylated residue can generate the phosphorylation of additional residues (Flotow et al., 1990). The complex pattern of VRK1 autophosphorylation made difficult to identify the specific residues phosphorylated and their biological consequence. This property of the casein kinase family might explain that the phosphorylation of Thr-18 by CK1D requires the previous phosphorylation of the
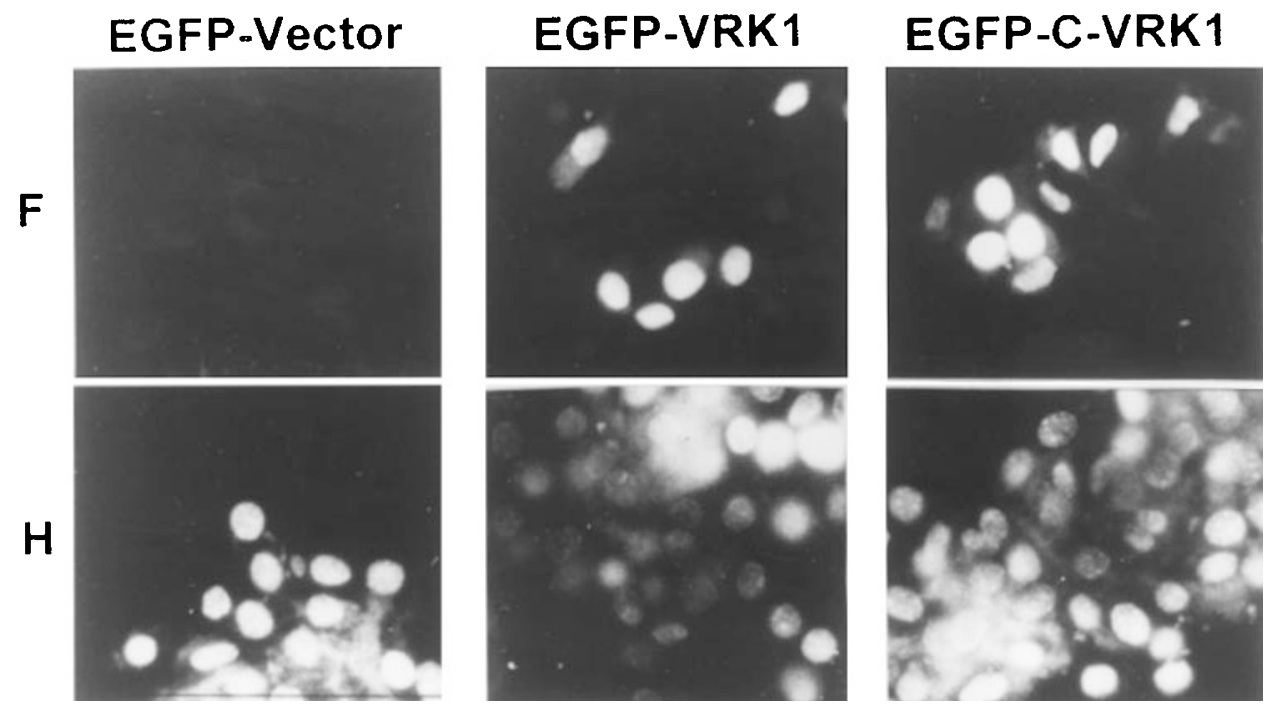

Figure 4 Nuclear localization of VRK1 protein. NIH3T3 fibroblasts were transiently transfected with pEGFP-C1 (vector), pEGFP-VRK1, and pEGFP-C-VRK1 (carboxy terminus) constructs. At the top is shown the green fluorescence (F) and at the bottom the staining with Hoechst dye $(\mathrm{H})$ to identify the nuclei. EGFP is the control with only the empty vector. EGFP-VRK1 is the full length VRK1 fused in frame to the EGFP protein; and the EGFP-C-VRK1 is the carboxy terminus (residues 268-396) fused to EGFP 
proximal Ser-15 (Dumaz et al., 1999; Sakaguchi et al., 2000).

The tumour suppressor protein p53 integrates multiple signals such as DNA damage, metabolic changes, hypoxia, spindle damage, viral infection, cytokine responses, heat shock and activated oncogenes among others (Levine, 1997; Meek, 1998a; Prives and Hall, 1999). The p53 protein plays many roles in several different aspects of cell biology (Brown and Wouters, 1999; Ko and Prives, 1996; Levine, 1997; Prives and Hall, 1999). However the role of p53 is very complex, and many of the regulatory processes are not yet integrated. (Brown and Wouters, 1999). The p53 Nterminal domain is regulated by phosphorylation (Meek, 1998b). P53 has a region (amino acids 1329), which mediates the interaction between p53 and the mdm-2 protein (Chen et al., 1993; Dobbelstein et al., 1999; Lin et al., 1994; Shieh et al., 1997). This p53 binding site is highly conserved in many species (Levine, 1997). The hydrophobic residues Leu-14 and Phe-19 are crucial for the p53-mdm-2 interaction (Lin et al., 1994). Thr-18 is next to Phe-19 that is directly implicated in the p53 binding to $\mathrm{mdm}-2$, by inserting deep into the mdm-2 cleft (Kussie et al., 1996). This hydrophobic residue enters into a cleft within the mdm-2 protein as demonstrated by crystallographic studies (Kussie et al., 1996). It is therefore reasonable to expect that the introduction of a phosphoryl group in this p53 region will interfere with its entry in the mdm-2 hydrophobic cleft, disrupting in that way the union of the two proteins.

Phosphorylation of $\mathrm{p} 53$ in this region can have important biological consequences, that might vary depending on the residue phosphorylated, and interfere with the p53 binding to the inhibitor mdm-2 protein (Shieh et al., 1997). Ser-15 phosphorylation, as a consequence of DNA damage, is carried out by the double-strand DNA-dependent kinase (Shieh et al., 1997; Siliciano et al., 1997), and by the ATM protein (Banin et al., 1998; Canman et al., 1998). Phosphorylation of different $\mathrm{p} 53$ residues in this region alters the role of $\mathrm{p} 53$ as transcription factor, this activity is more sensitive to Ser-15 phosphorylation, than the phosphorylation of Thr-18 or Ser-20, and is mediated by the interaction with the p300 protein (Dumaz and Meek, 1999). ATM phosphorylates Ser-15 impairing p53 apoptotic activity, and probably affecting also cell growth, or cell transformation (Unger et al., 1999), and alleviates inhibition by mdm-2 (Shieh et al., 1997). Therefore, phosphorylation might be a mechanism of modulating the interaction of p53 with other proteins, such as mdm-2 or p300. The result of p53 phosphorylation in Thr-18 is likely to be the accumulation of a form of p53 that is not sensitive to inhibition, because it can not be sequestered.

Phosphorylation of p53 in Thr-18 suggests what might be its biological consequences, based on our current understanding of p53 biology on the control of cell cycle and apoptosis (Levine, 1997; Meek, 1998a; Prives and Hall, 1999). This phosphorylation might prevent $\mathrm{p} 53$ binding to $\mathrm{mdm}-2$ and result in a block of the p53 shuttling between the nuclei and the cytoplasm. Two kinases phosphorylate Thr-18, casein kinase 1D (Dumaz et al., 1999; Sakaguchi et al., 2000) and VRK1 (this study). This phosphorylation might be an alternative route to the effect by p19ARF that also

prevents p53 translocation by blocking the shuttling effect of mdm-2 (Sherr, 1998; Tao and Levine, 1999). In this context the VRK1 nuclear kinase is a novel upstream regulator of $\mathrm{p} 53$ which must be implicated in some type of response to some of these signals by a not yet characterized pathway. The regulation of VRK1 is likely to be mediated by the interactions of its unique C-terminus region, which also mediates its nuclear localization signal. The protein-protein interactions of this C-terminus might lead to the identification of other elements of this novel pathway.

The identification and characterization of the specific kinases involved in p53 phosphorylation will be an important step in the elucidation of $\mathrm{p} 53$ regulation. In this study we have characterized a new kinase, VRK1, that phosphorylates p53. The physiological role of VRK1 is not yet known, but its expression in many cell types (Nezu et al., 1997), suggests the existence of a novel regulatory pathway upstream of p53 that will require further experimental work on the role of this new kinase family. VRK1 is a novel nuclear serinethreonine kinase that opens up a new, and unknown, level of p53 regulation. It presents new questions regarding the physiological role of the new kinase. Such as how it is regulated, to what kind of stimuli does it respond, what role does VRK1 autophosphorylation play in the regulation of its own activity, what other cellular proteins are regulated by it, and what proteins interact and regulate VRK1 activity. It is expected that future work will answer these new issues and open new lines of work, particularly in the complex area of $\mathrm{p} 53$ regulation, where the different signals have to be temporally integrated in the physiology of the cell.

\section{Materials and methods}

\section{Fusion proteins, kinase substrates and vectors}

Casein, histones $2 \mathrm{~A}$ and 3, phosvitin, myelin basic protein, and heparin were from Sigma (St. Louis, MO, USA). $\left[{ }^{32} \mathrm{P}-\gamma\right]-$ ATP was from Amersham (Little Chalfont, UK). The GSTjun $(1-79)$ fusion protein was a gift of Michael Karin (University of California, San Diego, USA). GST-ATF2 protein was obtained from Dr S Gutkind (N.I.H., Bethesda, MD, USA). GST-p53 (murine) constructs, FP221 (1-85), FP267 (1-67), FP279 (11-63) and FP380 (1-85 with Ser 4, 6 and 9 mutated to Ala) were provided by Dr DW Meek (Dundee University, Scotland, UK) (Milne et al., 1992; 1994). Some of these p53 constructs were used as substrates to generate additional specific aminoacid substitutions. The green fluorescent protein vector pEGFP-C1 was from Clontech (San Diego, CA, USA).

\section{Isolation of RNA and cDNA synthesis}

Total RNA was extracted from HeLa cells using Trizol (Life Technologies). The synthesis of cDNA has been previously reported (Ferrer et al., 1999). From this cDNA $1 \mu$ l was used as substrate to amplify by PCR different fragments of the cDNA in order to make different constructions of fusion proteins with different types of expression vectors.

\section{Primers used for PCR and cloning}

To generate full length and the carboxy terminal domain of VRK1 we used different primers designed based on the 
human VRK1 sequence (GenBank AB000449) as reference (Nezu et al., 1997). VRK1: 5'-CCCGGATCCATGCCTCGTGTAAAAGCAGCTAAGCTG-3' (nt 76-103), this primer has the initiation codon and a BamHI cloning site. VRK2X: 5'-GGGTCTAGATTATTCTGGACTCTCTTTCTGGTTCTTGAACGGG-3' (nt 1232-1269 antisense strand), with a $X b a I$ cloning site and the termination codon. VRK2S: 5'GGGGTCG ACTTATTCTGGA CTCTCTTTCTGGTTCTTGAACGGG-3' (nt 1232-1269 antisense strand), with a SalI cloning site and the termination codon. VRKIT: 5'-CCCGGATCCCCTAAATATGTTAGAGATTCC-3' (nt 877897) with a BamHI restriction site for cloning. The fulllength protein was made with primers VRK1B and VRK1X or VRK1S. For the C-terminus primers VRK1T and VRK1X or VRK1S were used. The PCR reaction mix contained $1 \mu \mathrm{l}$ of cDNA product, 2 units of Thermus brockianus polymerase, and $1.5 \mathrm{mM} \mathrm{Mg} \mathrm{CL} \mathrm{CL}_{2}$ in buffer supplied by manufacturer (Fynnzymes, Espoo, Finland). The amplification protocol consisted of 1 cycle at $95^{\circ} \mathrm{C}$ for $5 \mathrm{~min}, 30$ cycles $\left(95^{\circ} \mathrm{C} 30 \mathrm{~s}\right.$, $56^{\circ} \mathrm{C} 30 \mathrm{~s}, 72^{\circ} \mathrm{C} 30 \mathrm{~s}$ ), and a final elongation cycle at $72^{\circ} \mathrm{C}$ for $5 \mathrm{~min}$.

\section{Glutathione S-transferase fusion proteins}

We constructed fusion proteins using vector pGEX-4T-1 (Pharmacia Biotech, Uppsala, Sweden). These fusion proteins have the complete VRK1 coding region (GST-VRK1), with residues $1-396$, and the $\mathrm{C}$-terminal domain of 128 amino acids, residues 268-396 (GST-C-VRK1). The fusion proteins were purified with glutathione-agarose beads and eluted with reduced glutathione as suggested by the manufacturer. Other proteins used as kinase substrates were also fused to GST.

\section{Kinase activity assay}

Kinase activity was determined by assaying protein phosphorylation in a mixture containing $20 \mathrm{~mm}$ Tris- $\mathrm{HCl}, \mathrm{pH} 7.5$, $5 \mathrm{mM} \mathrm{MgCl}_{2}, 0.5 \mathrm{mM}$ dithiothreitol, $150 \mathrm{mM} \mathrm{KCl}$ and $5 \mu \mathrm{M}$ $(5 \mu \mathrm{Ci}) \gamma-\left[{ }^{32} \mathrm{P}\right] \mathrm{ATP}$ with approximately $5 \mu \mathrm{g}$ of GST-VRK1 protein and $10 \mu \mathrm{g}$ of another protein as substrate when indicated. The reaction was routinely performed for $3 \mathrm{~h}$ at $30^{\circ} \mathrm{C}$.

\section{Acid hydrolysis and phosphoaminoacid analysis}

An autophosphorylation reaction was performed with the GST-VRK1 protein. The phosphorylated protein was fractionated by an SDS-polyacrylamide electrophoresis and transferred to an Immobilon-P filter (Millipore, Bedford, MA, USA) and the radioactive band was cut and the protein eluted. The eluted protein was hydrolysed with $200 \mu$ l of $6 \mathrm{~N}$ $\mathrm{HCl}$ at $110^{\circ} \mathrm{C}$ for $2 \mathrm{~h}$. The sample was freeze-dried and resuspended in a mixture containing $2 \mu \mathrm{l}$ of a stock solution at $1 \mathrm{mg} / \mathrm{ml}$ of P-Ser, P-Thr and P-Tyr as reference markers, $1 \mu \mathrm{l}$ of $1 \%$ bromophenol blue and $2 \mu \mathrm{l}$ of formic acid/acetic acid/water $(1: 3.1: 3.5)$ mix at $\mathrm{pH} 1.9$. The mixture was applied to a cellulose chromatoplaque (Merck) and subject to flat bed electrophoresis in a Multiphor II system (Pharmacia, Sweden) at $1.5 \mathrm{KV}$ for $90 \mathrm{~min}$. The plate was left to air dry and after humidifying in a solution with acetic acid/pyridine/ water $(10: 1: 139)$ at $\mathrm{pH} 3.5$ was electrophoresed in a second dimension at $1.5 \mathrm{KV}$ for $30 \mathrm{~min}$. After drying, the radioactivity on the plate was analysed with a FujiBas 1000 phosphorimager (Fuji, Japan) or exposed to X-ray film. The phosphoaminoacid markers were detected by staining with a $0.25 \%$ ninhydrin solution in acetone.

\section{Site-directed mutagenesis}

Several Ser and Thr residues in the VRK1 protein were replaced by introducing point mutations with the Quickchange site-directed mutagenesis kit (Stratagene, San Diego,
CA, USA). To make the mutation we designed two long complementary oligonucleotides containing the desired mutation and they were used to copy the target plasmid with $P f u$ polymerase. The input DNA was degraded by digestion with $D p n I$ and the remaining DNA was used to transform E. coli $\mathrm{DH} 5 \alpha \mathrm{F}$ strain. The clones with the mutation were confirmed by nucleotide sequencing. The amino acid changes made in GST-VRK1 fusion protein were S14A, T102A, S125G, S150A, S158G, S239A, T305A, T312A, T355A and T390A. The clones were named after the mutation.

Amino acid substitutions in all Ser or Thr residues within the first 63 amino acids of the GST-p53 (murine) fusion protein were made in the same way. The amino acid changes introduced in FP279 p53 were S151, T18A, S20A, S34A, S55N and S61A. The T18A change was also introduced in FP221 and FP380. All mutations were confirmed by DNA sequencing.

\section{Phosphopeptide map analysis}

Autophosphorylated proteins were fractionated in a SDSPAGE gel and transferred to an Immobilon-P membrane. The band with the phosphorylated protein was cut, incubated with $0.5 \%$ polyvinyl-pyrrolidone in $100-\mathrm{mm}$ acetic acid for $30 \mathrm{~min}$ at $37^{\circ} \mathrm{C}$, followed by extensive washes with water and fresh $50 \mathrm{mM} \mathrm{NH}_{4} \mathrm{HCO}_{3}$. The membrane was incubated twice, with $10 \mu \mathrm{g}$ of trypsin (Roche Diagnostics, Mannheim, Germany) in $50 \mathrm{~mm} \mathrm{NH} \mathrm{NHCO}_{3}, \mathrm{pH} 8.0$ for $2 \mathrm{~h}$ at $37^{\circ} \mathrm{C}$, and a third time for $18 \mathrm{~h}$. The membrane was extensively washed with sterile distilled water. The washes were freezedried, and oxidised with 9:1 performic acid/hydrogen peroxide for $1 \mathrm{~h}$ at room temperature, followed by freezedrying. The sample was resuspended in $5 \mu \mathrm{l}$ of formic acid: acetic acid: water $(1: 3,12: 35.88) \mathrm{pH} 1.9$ and applied to a chromatoplaque (Merck, Darmstadt, Germany). The first dimension was an electrophoresis at $1.5 \mathrm{~K}$ volt for $90 \mathrm{~min}$ in a Multiphor system (Pharmacia, Uppsala, Sweden). The plaque was left to air dry, and turned. The second dimension was a chromatography performed in acetic acid: pyridine: nbutanol: water $(1: 3.33: 5: 4)$ for $13 \mathrm{~h}$. The plaque was left to dry and radioactivity was detected using an X-ray film or by a phosphorimager FUJI BAS 1000 (Fuji, Japan).

\section{Transfections}

NIH3T3 fibroblasts were grown in DMEM supplemented with $5 \%$ calf serum with $5 \% \mathrm{CO}_{2}$ in a humidified atmosphere. NIH3T3 fibroblasts were transfected with the calcium phosphate method using a commercial kit (Promega, Madison, WI, USA). The cells were transfected with $5 \mu \mathrm{g}$ of plasmid DNA from the different construct with the green fluorescent protein. After transfection, the cells were plated in $100-\mathrm{mm}$ dishes containing several glass cover slips at the bottom. The cells growing on cover slips were analysed $48 \mathrm{~h}$ after transfection for the expression of the transfected proteins. Immunofluorescence was visualised and photographed with a Zeiss Axiophot microscope.

\section{Abbreviations}

VRK1, vaccinia related kinase 1; CK1, casein kinase1; GST, glutathione-S-transferase; EST, expressed sequence tag.

\section{Acknowledgements}

S Lopez-Borges was supported by a fellowship from Comunidad de Madrid. This work was supported by grants to PA Lazo from Fondo de Investigación Sanitaria (FIS98-0313), Comunidad de Madrid (08.1-0004-98), and Comisión Interministerial de Ciencia y Tecnologia (SAF00/ 0169). 


\section{References}

Banham AH and Smith GL. (1992). Virology, 191, 803-812.

Banin S, Moyal L, Shieh S, Taya Y, Anderson CW, Chessa L, Smorodinsky NI, Prives C, Reiss Y, Shiloh Y and Ziv Y. (1998). Science, 281, 1674-1677.

Beaud G, Beaud R and Leader DP. (1995). J. Virol., 69, $1819-1826$.

Bellacosa A, Chan TO, Ahmed NN, Datta K, Malstrom S, Stokoe D, McCormick F, Feng J and Tsichlis P. (1998). Oncogene, 17, 313-325.

Bottger V, Bottger A, Garcia-Echeverria C, Ramos YF, van der $\mathrm{Eb}$ AJ, Jochemsen AG and Lane DP. (1999). Oncogene, 18, 189-199.

Brown JM and Wouters WG. (1999). Cancer Res., 59, 1391 1399.

Canman CE, Lim DS, Cimprich KA, Taya Y, Tamai K, Sakaguchi K, Appella E, Kastan MB and Siliciano JD. (1998). Science, 281, 1677-1679.

Ceci JD, Patriotis CP, Tsatsanis C, Makris AM, Kovatch R, Swing DA, Jenkins NA, Tsichlis PN and Copeland NG. (1997). Genes Dev., 11, 688-700.

Craig AL, Burch L, Vojtesek B, Mikutowska J, Thompson A and Hupp TR. (1999). Biochem J., 342, 133-141.

Chehab NH, Malikzay A, Stavridi ES and Halazonetis TD. (1999). Proc. Natl. Acad. Sci. USA, 96, 13777-13782.

Chen J, Marechal V and Levine AJ. (1993). Mol. Cell. Biol. 13, $4107-4114$.

Dingwall C and Laskey RA. (1991). Trends Biochem. Sci., 16, $478-481$.

Dobbelstein M, Wienzek S, Konig C and Roth J. (1999). Oncogene, 18, 2101-2106.

Dumaz N and Meek DW. (1999). EMBO J, 18, 7002-7010.

Dumaz N, Milne DM and Meek DW. (1999). FEBS Lett, 463, $312-316$.

Ferrer M, Lopez-Borges S and Lazo PA. (1999). Oncogene, 18, 2253-2259.

Flotow H, Graves PR, Wang A, Fiol CJ, Roeske RW and Roach PJ. (1990). J. Biol. Chem., 265, $14264-14269$.

Flotow H and Roach PJ. (1991). J. Biol. Chem., 266, $3724-$ 3727.

Giaccia AJ and Kastan MB. (1998). Genes Dev., 12, 2973 2983.

Graves PR and Roach PJ. (1995). J. Biol. Chem., 270, $21689-21694$

Gross SD and Anderson RA. (1998). Cell. Signal., 12, $699-$ 711.

Hall-Jackson CA, Cross DAE, Morrice N and Smythe C. (1999). Oncogene, 18, 6707-6713.

Hirao A, Kong YY, Matsuoka S, Wakeham A, Ruland J, Yoshida H, Liu D, Elledge SJ and Mak TW. (2000). Science, 287, $1824-1827$.

Hunter T. (1995). Cell, 80, 225-236.

Karin M and Hunter T. (1995). Curr. Biol., 5, 747- 757.

Kloss B, Price JL, Saez L, Blau J, Rothenfluh A, Wesley CS and Young MW. (1998). Cell, 94, 97-107.

Knippschild U, Milne D, Campbell L and Meek D. (1996). Oncogene, 13, 1387-1393.

Knippschild U, Milne DM, Campbell LE, DeMaggio AJ, Christenson E, Hoekstra MF and Meek DW. (1997). Oncogene, 15, 1727-1736.

Ko LJ and Prives C. (1996). Genes Dev., 10, 1054-1072.
Ko LJ, Shieh S, Chen X, Jayaraman L, Tamai K, Taya Y, Prives C and Pan Z. (1997). Mol. Cell. Biol., 17, 72207229.

Kussie PH, Gorina S, Marechal V, Elenbass B, Moreau J, Levine AJ and Pavletich NP. (1996). Science, 274, $948-$ 953.

Lakin ND, Hann BC and Jackson SP. (1999). Oncogene, 18, $3989-3995$.

Lakin ND and Jackson SP. (1999). Oncogene, 18, $7644-$ 7655.

Levine A. (1997). Cell, 88, 323-331.

Lin J, Chen J, Elenbass B and Levine AJ. (1994). Genes Dev., 8, $1235-1246$.

Lin S, Chen W and Broyles SS. (1992). J. Virol., 66, $2717-$ 2723.

Meek DW. (1998a). Cell. Signal, 10, 159-166.

Meek DW. (1998b). Int. J. Radiat. Biol., 74, $729-737$.

Meek DW. (1999). Oncogene, 18, 7666-7675.

Melchior F and Gerace L. (1998). Trends Cell Biol., 8, $175-$ 179.

Milne DM, Campbell DG, Caudwell FB and Meek DW. (1994). J. Biol. Chem., 269, $9253-9260$.

Milne DM, Campbell LE, Campbell DG and Meek DW. (1995). J. Biol. Chem., 270, 5511-5518.

Milne DM, Palmer RH, Campbell DG and Meek DW. (1992). Oncogene, 7, 1361-1369.

Nezu J, Oku A, Jones MH and Shimane M. (1997). Genomics, 45, 327-331.

Powers MA and Forbes DJ. (1994). Cell, 79, 931-934.

Price JL, Blau J, Rothenfluh A, Abodeely M, Kloss B and Young MW. (1998). Cell, 94, 83-95.

Prives C and Hall PA. (1999). J. Pathol., 187, 112-126.

Rempel RE, Anderson MK, Evans E and Traktman P. (1990). J. Virol., 64, 574-583.

Rempel RE and Traktman P. (1992). J. Virol., 66, 44134426.

Sakaguchi K, Saito S, Higashimoto Y, Roy S, Anderson CW and Appella E. (2000). J. Biol. Chem, 275, $9278-9283$.

Sherr CJ. (1998). Genes Dev., 12, 2984-2991.

Shieh S, Ikeda M, Taya Y and Prives C. (1997). Cell, 91, $325-334$

Shieh SY, Ahn J, Tamai K, Taya Y and Prives C. (2000a). Genes Dev., 14, 289-300.

Shieh SY, Taya Y and Proves C. (2000b). EMBO J., 18, $1815-1823$.

Siliciano JD, Canman CE, Taya Y, Sakaguchi K, Appella E and Kastan MB. (1997). Genes Dev, 11, 3471-3481.

Tao W and Levine AJ. (1999). Proc. Natl. Acad. Sci. USA, 96, 6937-6941.

Tibbetts RS, Brumbaugh KM, Williams JM, Sarkaria JN, Cliby WA, Shieh SY, Taya Y, Prives C and Abraham RT. (1999). Genes Dev, 13, 152-157.

Traktman P, Anderson MK and Rempel RE. (1989). J. Biol. Chem., 264, 21458-21461.

Tuazon PT and Traugh JA. (1991). Adv. Sec. Mess. Phosphoryl. Res., 23, $123-164$.

Unger T, Sionov R, Moallen E, Yee CL, Howley PM, Oren M and Haupt Y. (1999). Oncogene, 18, 3205-3212.

Weigel NL. (1996). Biochem. J., 319, 657-667. 